The evidence, however, seems to point very strongly to this conclusion. I very much hope that these facts will be brought to the attention of some one who has an opportunity for physiologic experiments on water-drinking, and that this may lead the way to experiments that will show definitely whether or not nitrates in water can reach a proportion sufficiently great to be in themselves harmful.

\section{THE DIAGNOSTIC SIGNIFICANCE OF THE URINARY METHYLENE-BLUE REACTION WITH SPECIAL REFERENCE TO MALIGNANCY

\author{
PRELIMINARY REPORT
}

JACOB FUHS, M.D.

Consulting Physician, Long Island College and Brooklyn German Hospitals, etc.; Attending Physician to St. Catherine's and Jewish Hospitals

AND

WILLIAM LINTZ, M.D.

Associate Professor of Bacteriology, Long Island College Hospital; Assistant in Medicine, Kings County and Jewish Hospitals BROOKLYN

In searehing for the presence in the urine of abnormal products of elimination in cases of malignant disease, we observed that methylene-blue was decolorized by the urine taken from these patients. Repeated examinations and more extensive investigations demonstrated that urines in cases of rheumatism, nephritis, meningitis, etc., were also sometimes decolorized, but generally to a minor and variable degree. In most instances the latter conditions could be easily differentiated and eliminated, so that it appears as if this reaction may have considerable value in the diagnosis of malignant disease.

It is for this reason deemed justifiable, at this early stage, to make this brief preliminary report, so that other observers may investigate the value of this test by experimenting on a larger number of cases.

So far, this test has been positive in every well-established case of malignant disease. Many of these cases have been corroborated by operations and post-mortem and pathologic diagnosis. Though this test is not specific for malignant disease, occurring as it does with great constancy, particularly in pregnancy, also sometimes in nephritis, rheumatism, meningitis and in other conditions, it has proved already of considerable practical value in the diagnosis of malignant disease. As this test is extremely simple, and as no special apparatus or skill is required, it can be readily and quickly carried out by anybody anywhere. The decided and striking change of color leaves no doubt as to the presence or absence of the reaction.

\section{TECHNIC OF TEST}

Methylene-blue-we generally use 3 to 5 drops of Löffler's methylene-blue - is added to a test-tubeful of fresh urine; sufficient anilin dye is used to give it a decided blue color. The urine is shaken and then allowed to stand at room temperature for from twelve to twenty-four hours. A control fresh specimen of normal urine similarly treated is made. At the end of said time the blue color of the urine disappears; the upper layer, however, which is in contact with the air, still remains more or less blue. The control specimen, on the other hand, remains unchanged, retaining its uniform blue color.

More detailed investigations have already been instituted so as to further augment the scope of this test. For many tests made we have to thank the interns of the following hospitals: Dr. C. Breitman of the Brooklyn Jewish Hospital, Dr. W. Phipard of the Long Island College Hospital and Dr. C. R. Hutchins of St. Catherine's Hospital.

The accompanying table illustrates the above points.

\begin{tabular}{|c|c|c|c|}
\hline & URINARY METHYLENE-BLUE REA & ICTIONS & \\
\hline No. of Cases. & Diagnoses. & Positive. & Negat \\
\hline 34 & Carcinoma (well established). . & 34 & 0 \\
\hline 1 & Sarcoma (well establisbed)... & 1 & 0 \\
\hline 5 & Tumor (type unknown) ..... & 5 & 0 \\
\hline 1 & 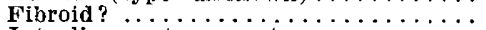 & 0 & 1 \\
\hline $\mathbf{1}$ & Intraligamentous cyst $\ldots \ldots$ & 0 & 1 \\
\hline 1 & Hydatid cyst of liver........ & 0 & 1 \\
\hline 1 & Small glandular swelling of breast... & 0 & 1 \\
\hline 2 & Hodgkin's disease $\ldots \ldots \ldots \ldots \ldots \ldots$ & 2 & 0 \\
\hline 1 & Banti's disease. & 0 & 1 \\
\hline $2 \overline{3}$ & Pregnancy (all cases in late stage)... & 22 & 1 \\
\hline 1 & Incomplete abortion $\ldots . . \ldots \ldots \ldots$ & 0 & 1 \\
\hline 16 & Post partum $\ldots \ldots \ldots \ldots \ldots \ldots \ldots$ & 6 & 10 \\
\hline 3 & Miscarriage. & 2 & 1 \\
\hline 2 & Complete abortion $\ldots \ldots \ldots$ & 0 & 2 \\
\hline $\mathbf{2}$ & Pyelitis of pregnancy....... & 0 & 2 \\
\hline 1 & Post-partum sepsis........ & 0 & 1 \\
\hline 5 & Nephrolithiasis ......... & 3 & 2 \\
\hline 11 & Nephritis ..... & 4 & $\overline{7}$ \\
\hline 4 & Hematogenous infection of kidney.... & 3 & 1 \\
\hline 3 & Uremic coma and chronic neplitis.. & 1 & 2 \\
\hline 3 & Chronic catarrhal gastritis . . . . . . & 0 & 3 \\
\hline 7 & Gastric ulcer $\ldots \ldots \ldots \ldots \ldots \ldots \ldots$ & 0 & 7 \\
\hline 2 & Pyloric ulcer with induration $\ldots \ldots \ldots$ & 1 & i \\
\hline$\overline{4}$ & Duodenal ulcer $\ldots \ldots \ldots \ldots \ldots \ldots$ & 0 & 4 \\
\hline 1 & Intestinal ulcerations $\ldots$ & 0 & 1 \\
\hline 1 & Amebic dysentery ... & 0 & 1 \\
\hline$\overline{2}$ & Enteroptosis with excessive peristulsis. & 0 & 2 \\
\hline$\overline{1}$ & Peritonitis $\ldots \ldots \ldots \ldots \ldots \ldots \ldots$ & 0 & 1 \\
\hline 2 & Chronic catarrhal colitis.......... & 0 & 2 \\
\hline$\overline{2}$ & Appendicitis $\ldots \ldots \ldots \ldots \ldots \ldots \ldots$ & 0 & 2 \\
\hline 1 & Catarrhal jaundice ....... & 0 & $\mathbf{1}$ \\
\hline 11 & Cholelithiasis $\ldots \ldots \ldots \ldots$ & 0 & 11 \\
\hline 1 & Acute cholecystitis & 0 & $\hat{1}$ \\
\hline 1 & Chronic cholecystitis & 0 & 1 \\
\hline 1. & Cholecystitis and mitral stenosis.... & 0 & $\mathbf{1}$ \\
\hline 4 & Acute endocarditis $\ldots \ldots \ldots \ldots \ldots$ & 2 & 2 \\
\hline 4 & Pericarditis $\ldots \ldots \ldots \ldots \ldots \ldots \ldots \ldots$ & 0 & 4 \\
\hline 3 & Senility with arteriosclerosis...... & 2 & $\mathbf{1}$ \\
\hline 1 & 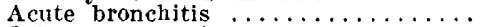 & $\overline{0}$ & 1 \\
\hline $1 \overline{7}$ & Lobar pneumonia $\ldots \ldots \ldots \ldots \ldots$ & 1 & $1 \overline{6}$ \\
\hline 3 & Fmpyema $\ldots \ldots \ldots \ldots \ldots \ldots \ldots \ldots$ & 1 & 2 \\
\hline 22 & Articular rheumatism $\ldots \ldots$. & 1 & $2 \overline{1}$ \\
\hline 1 & Gonorrheal rheumatism $\ldots \ldots$ & 0 & 1 \\
\hline 6 & Typhoid fever $\ldots \ldots \ldots \ldots \ldots \ldots \ldots$ & 0 & 6 \\
\hline 2 & Brill's disease $\ldots \ldots \ldots \ldots \ldots \ldots$ & 1 & 1 \\
\hline 2 & Influenza $\ldots \ldots \ldots \ldots \ldots \ldots \ldots$ & 0 & 2 \\
\hline 1 & Pyemia & 0 & 1 \\
\hline 4 & Diabetes (two with gangreno) . . . . . & 2 & 2 \\
\hline 1 & $\ldots \ldots \ldots \ldots \ldots \ldots \ldots \ldots$ & $\overline{0}$ & $\mathbf{1}$ \\
\hline 1 & $\ldots \ldots \ldots \ldots \ldots$ & 1 & 0 \\
\hline 5 & Tuberculous meningitis $\ldots \ldots \ldots \ldots$ & 2 & $\therefore$ \\
\hline 1 & Anterior poliomyelitis & $\overline{1}$ & 0 \\
\hline $\mathbf{1}$ & Temporal neuralgia with mitral & & \\
\hline & stenosis $\ldots \ldots \ldots \ldots$ & 1 & 0 \\
\hline 2 & Acute salpingitis & 0 & 2 \\
\hline 1 & Bilharzia hamatobia (bladder). & 0 & $\mathbf{1}$ \\
\hline 1 & Hernia $\ldots \ldots \ldots \ldots \ldots \ldots \ldots$ & 0 & $\mathbf{i}$ \\
\hline 2 & Etemorrhoids & 1 & 1 \\
\hline 5 & Lacerated cervis and perinetum... & 1 & 4 \\
\hline 70 & Various surgical conditions other than & & \\
\hline & gnancy & 0 & 70 \\
\hline 19 & Disease not determined. & 4 & 15 \\
\hline 26 & Normal urines $\ldots \ldots \ldots \ldots \ldots \ldots \ldots$ & 0 & 26 \\
\hline
\end{tabular}

In most cases other than those of malignancy in which the test was positive, it became negative usually in subsequent examinations, as the condition from which the patient was suffering improved.

871 Park Place-907 St. Mark's Avenue.

\section{A CASE OF STRANGULATED HERNIA PRE- SENTING UNUSUAL SYMPTOMS}

JAMES R. JUDD, M.D. IIONOLULU, HAWAII

Patient.-A Chinaman; aged 64, a laborer, for the past fifteen years had been troubled by a rupture which had gradually increased in size. On several oecasions there had been difficulty in reducing the contents, but he had always finally succeeded. He had never used a truss. Four days previous to his admittauce to the hospital, the swelling had increased in size and he had been unable to reduce it. He had suffered considerable pain. The bowels had moved once. According to the patient's statement, which was corroborated by that of his friends and relatives, he had not vomited at all. 
Physical Examination.-The patient was a fairly well-nourished man; pulse was 120 ; temperature 101; respiration embarrassed. The abdomen was greatly distended and tympanitic. The right inguinal region showed a tense, tender swelling involving the right side of the scrotum. The skin over the swelling was reddened and edematous. There was no impulse on coughing. Rectal examination was negative.

Operation.-The usual incision disclosed a tense sac adherent to scrotum and containing a loop of gangrenous intestine, and the cavity of the sac filled with fluid feces. Gas and fecal material were seen to be escaping from two openings in the bowel. The sac was irrigated, the constriction relieved, and the gangrenous bowel wrapped in moist gauze. The loop of intestine was then brought well outside of the abdominal cavity and the distended bowel divided at a safe distance above the gangrenous area. This division allowed the escape of a large quantity of fluid feces and considerable gas. The gangrenous intestine $12 \mathrm{~cm}$. in length was removed, together with a wedge-shaped piece of mesentery, and an end-to-end anastomosis effected with sutures. The spermatic cord was found to be flattened out by pressure and pulsation was absent in the vessels. The right testis was greenish-black in color and did not bleed on incision. Accordingly the cord was ligated off and removed together with the testis. The sac, very much thickened and adherent, was removed and the neck sutured at the internal ring. The closure of the inguinal canal was then effected in the usual manner. Drainage was provided for at the lowest end of the wound.

Except for a slight discharge from the drainage tract, the wound healed by primary union. The patient made an uneventful recovery and was discharged in three weeks in good general condition and with a firm wound.

\section{COMMENTS}

Vomiting has long been regarded as an essential symptom of intestinal obstruction caused by strangulated hernia and is so taught to students. A review of the literature at my disposal produces the following opinjons: Vomiting at first of stomach contents and later of fecal material is evidently considered as an essential symptom in the following systems: Keen's "Surgery," "International Text-Book," "American Text-Book," Dennis' "System of Surgery," Von Bergmann's "System"; also in the surgical works of Ashhurst, Erichsen, Jacobson, Pick, Walsham, Tillmann, Spencer and Gask, and DaCosta. Sir James Paget in his "Clinical Lectures" says, "If I were asked which of the signs of strangulation I would most rely on as commanding the operation, I should certainly say the vomiting." "The only exception made is by Treves who writes in his System, "Vomiting appears early, is a marked and almost constant symptom.

The gangrenous condition of the testis was evidently caused by pressure of the sac and contents on the spermatic cord. This must be a very unusual occurrence, as no mention is made of it in any of the above text-books.

\section{HUGE HYDRONEPHROSIS (TWO GALLONS CAPACITY)}

H. J. WHIT ACRE, B.S., M.D. CINCIXXATI

Hydronephrosis is not an unusual lesion, and a distention of the pelvis of the kidney to a capacity of one or even two pints is perhaps not rare. A distention of the pelvis, however, to produce a cyst occupying the greater part of the abdominal cavity and containing more than two gallons of fluid is sufficiently unusual to justify a record of the case.

History-Mrs. W., aged 68 , gives a report of very good health previous to her present trouble, which began about twenty years ago. Her first symptom was a very peculiar sensation in the right leg, while walking, which extended from the thigh downward, and within half an hour she could not raise the foot from the floor. There was no pain elsewhere. One month later she had a second attack of sharp pain which commenced in the back on the right side and extended downward into the lower abdomen and into the thigh and leg in precisely the same manner as the first attack. There was very great nausea at this time, but no urinary symptoms. Similar attacks recurred until sixteen years ago, when she suffered from a severe attack of "gastric disturbance," which was eharacterized by very intense pain in the lumbar and right iliac region. Her physician diagnosticated her condition at the time as one of gas accumulation and obstruction. (It seems to me that a stone must have become lodged in the ureter at this time to cause a permanent total obstruction of the ureter.) The acute symptoms promptly subsided, but the swelling remained as a soft tumor mass in the right side of the abdomen. During the next several years the patient suffered frequently from stomach and liver attacks, as she designates them. The tumor remained about stationary in size during this period and could always be felt. Four years ago she had a very severe attack of abdominal trouble associated with gastric irritability and severe pain in the right side, particularly in the region of the liver. During the past four years the tumor has increased greatly in size and she had many attacks of pain. She has never suffered from bladder irritability, passes a normal amount of urine, and has never noticed anything abnormal in the appearance of the urine. Her main symptoms seems to be referable to the stomach. There have been no symptoms referable to the genitalia.

Physical Examination.-When seen for the first time on March 20, 1911, the patient appeared to be very well nourished and in fairly good health. The examination was negative, except for the abdomen, which showed a symmetrical enlargement equal to that of a seven or eight months' pregnancy. On palpation a distinet cystic tumor oceupying the greater part of the abdominal cavity could be easily made out, but the right half of the abdomen and the right flank was distinetly more tensely filled out than the left. A fluid wave was easily determined. The middle of the abdomen-indeed the greater part of the abdomen - was flat on percussion and a tympanitic note was given on the left side and above the cyst. (No great importance was given before operation to the fact that a tympanitic note was not elicited on the right side because all other physical signs seemed to point so definitely to a large ovarian cyst.) Bimanual examination showed the uterus to be normal and the fluid wave was easily communicated from the tumor above to the examining finger below. A diagnosis of ovarian cyst was made.

Operation.-A midline incision below the umbilicus demonstrated at once that the cyst was not attached to either ovary and that it was retroperitoneal. The peritoneum was then divided over the eyst, and a large ovarian cyst trocar inserted to draw off the fluid. Two gallons of fluid were withdrawn and perhaps one pint remained in the cyst, which was not measured. The cyst was then delivered by a blunt dissection, which extended as far upward as the liver, without much hemorrhage. A large artery and a large vein were cut between clamps and later found to be the renal artery and vein. An examination now revealed no kidney on this side and a hurried examination demonstrated no special lesion in this ureter. The incision in the peritoneum was closed by continuous suture and abdomen closed without drainage. When the cyst was filled out with cotton the kidney could be easily demonstrated flattened out to a brown-paper thinness on one side of the cyst and the ureter, renal artery and vein could be seen.

This patient made a perfect recovery and is now entirely well.

108 East Auburn Avenue.

Aneurysm and Edema.-An aneurysm may compress and obstruct the flow of blood through one of the large veins and thereby produce edema.-J. B. Murfree, in Southern Medical Journal. 